\title{
The Effect of Bulk Density on Emission Behavior of Soil at Microwave Frequencies
}

\author{
V. K. Gupta and R. A. Jangid \\ Microwave Research Laboratory, Department of Physics, Raj Rishi Autonomous Government P.G. College, Alwar, \\ Rajasthan 301001, India \\ Correspondence should be addressed to V. K. Gupta, contactvkg@yahoo.co.in
}

Received 30 April 2011; Revised 18 October 2011; Accepted 1 December 2011

Academic Editor: Jean Pierre Wigneron

Copyright @ 2011 V. K. Gupta and R. A. Jangid. This is an open access article distributed under the Creative Commons Attribution License, which permits unrestricted use, distribution, and reproduction in any medium, provided the original work is properly cited.

\begin{abstract}
Dielectric constant and dielectric loss $\left(\varepsilon^{\prime}\right.$ and $\left.\varepsilon^{\prime \prime}\right)$ of different soil samples with bulk densities varying from 1.3 to $2.0 \mathrm{gm} / \mathrm{cm}^{3}$ are determined at a single microwave frequency $9.78 \mathrm{GHz}$ and at temperature $37.0^{\circ} \mathrm{C}$. Different bulk densities of same soil are achieved by filling the wave guide cell with an equal volume but a different mass of soil. Further, $\varepsilon^{\prime}$ and $\varepsilon^{\prime \prime}$ of these soil samples are also estimated by semiempirical model and compared with the experimental results. The values of $\varepsilon^{\prime}$ and $\varepsilon^{\prime \prime}$ increase as bulk density of the soil increases. In view of microwave remote sensing, the Fresnel reflectivity of soil is computed from the knowledge of the complex dielectric constant and the surface boundary condition. Using Kirchhoff's reciprocity theorem the microwave emissivity is estimated from Fresnel reflectivity of the surface. It is observed that the microwave emission from the soil surface inhibits as bulk density of soil increases. Further, the roughness of soil surface has been taken into consideration in the emissivity computation and observed that the emissivity increases with increasing roughness of the soil surface.
\end{abstract}

\section{Introduction}

Soil compaction or high bulk density of soil is important field of research due to agricultural importance. Soil compaction is the main form of soil degradation which alters the extent and configuration of the pore space. It can have adverse effects upon plants by increasing field saturated hydraulic conductivity, mechanical impedance to the growth of roots. In compacted layers, water, nutrients, and airflow towards the plant roots are also restricted. These restrictions may reduce the crop growth and, subsequently, the yield. There are various reasons associated with the increase in bulk density of arable soils classified as natural and anthropogenic. Conventional tillage practice and the use of heavy machinery and vehicular traffic on farmlands are important reasons for increasing bulk density of agricultural soil. The increasing bulk density of soil affects the dielectric properties of dry and moist soil $[1,2]$. Different studies [3-7] predict that the dielectric parameters of soil at microwave frequencies are the function of various properties of soil such as texture, moisture, bulk density, temperature, and salinity. The physical properties of the soil like texture and structure influence the amount of pore space and the distribution of pore space within soil matrix. Thus, pore space and bulk density significantly affect the dielectric properties of the moist soil.

In the present investigations, we have determined experimentally the dielectric constant $\left(\varepsilon^{\prime}\right)$ and dielectric loss $\left(\varepsilon^{\prime \prime}\right)$ of soil of given texture at a particular state of soil moisture content $(\mathrm{SMC}=5.0 \%)$ and at different bulk densities varying from 1.3 to $2.0 \mathrm{gm} / \mathrm{cm}^{3}$ at X-band microwave frequency. The determination of $\varepsilon^{\prime}$ and $\varepsilon^{\prime \prime}$ at X band microwave frequency is an important field of research because microwave remote sensing at X-band is appropriate for the surface soil moisture studies of top layer soil. However, L-band radiometry is recognized as a technique with a significant potential for providing spatial and temporal soil moisture variations [8]. The basic observable parameter for passive microwave remote sensing is the microwave emissivity $(e)$, which is a strong function of dielectric constant and roughness of soil. Further, the roughness of agricultural soil surfaces (RMS surface height and correlation length) lies in decimeter to millimeter range $[9,10]$ which are comparable to the wave length of 
X-band microwaves. Therefore, roughness of agricultural surface produces maximum effect on emission of $\mathrm{X}$ band microwaves. Hence, rough surface emissivity studies particularly at X-band have enormous utility. Thus, the dielectric study of soil at X-band microwave frequencies is very useful for microwave remote sensing of agricultural fields. Currently most of the passive microwave sensors on satellite platforms operated at high frequencies $(>7 \mathrm{GHz})$ [11]. But, recently launched SMOS of the European Space Agency (ESA) and Aquarius and HYDROS (satellite mission of NASA) and ALOS mission by JAXA are equipped with Lband radiometers. NASA is planning to launch Soil Moisture Active Passive (SMAP) mission in 2014 that will also utilize L-band radar and radiometer.

Further, the $\varepsilon^{\prime}$ and $\varepsilon^{\prime \prime}$ of the same soil samples are determined for same states of texture, SMC, and bulk densities by a semiempirical model given by Peplinski et al. [4]. This is a commonly used dielectric mixing model of soil which has the widest validity range of frequency and accounts for the important parameters of soil, including bulk density, soil texture and soil temperature. Peplinski et al. [4] have extended the dielectric mixing model of Dobson et al. [3]. Both models are identical except of the expressions of conductivity and the real part of the complex dielectric constant.

The scattering and emission behavior of a surface is governed by its geometrical and dielectric properties [12]. Hence, dielectric constant, emissivity, and backscattering coefficient of moist soil are closely related with the bulk density of the soil. The microwave emissivity of bare and smooth soil surface can be calculated by emissivity model [13]. The emissivity model is applicable for the uniform profile of temperature and dielectric constant of emissive media. At X-band microwave frequencies, the observational depth for remote sensing is not more than few centimeters, so that soil can be treated as uniform dielectric profile media. An expression for observational or penetration depth is the function of $\varepsilon^{\prime}$ and $\varepsilon^{\prime \prime}$ as described $[14,15]$ by (1):

$$
\delta_{p}=\frac{\lambda \sqrt{\varepsilon^{\prime}}}{2 \pi \varepsilon^{\prime \prime}}
$$

where $\delta_{p}$ is penetration depth, and $\lambda$ is wavelength, both in millimeter.

Equation (1) is derived, using the small angle approximation and assumes uniform properties of soil with depth. At X-band microwave frequencies $(\lambda=3.0 \mathrm{~cm})$, the observational depth is decided by the values of $\varepsilon^{\prime}$ and $\varepsilon^{\prime \prime}$ of dry and moist soils. It is of the order of millimeters to few centimeters.

Variation in the bulk density of agricultural soil over a long period can be detected by comparing the periodic results of microwave remote sensing of a pixel taking into account the variations of roughness, temperature, soil moisture, and soil cover. Hence, microwave remote sensing is very useful in bulk density studies of moist soils. The objective of this study is that to investigate the effect of bulk density on the responses of radiometer because of the fact that soil physical properties affect the electrical properties.

For smooth and isotropic bare soil surfaces, estimated values of microwave emissivities by model calculations lie between 0.3 and 0.9 depending on wetness of the soil. But experimental observations carried out for emissivity of real soil surfaces using different techniques (radiometer mounted on the truck in field experiment, a radiometer in aircraft and on satellite) show that the calculated values were never less than 0.6, irrespective of the wetness of the soil [16]. Schmugge et al. [17] proposed that such high values of observed emissivity are believed to be caused primarily by the effect of surface roughness. Although many approaches have been developed to determine emissivity of the rough surface, but we have used semiempirical model developed by Choudhury et al. [18]. However, recently developed model by Wigneron et al. [19] for L-band microwave emission of the biosphere (L-MEB) provides a good accuracy (better than $5 \mathrm{~K}$ ) over a large range of soil roughness and moisture conditions than Chaudhery approach.

Roughness of soil surface depends on the observation wavelength of electromagnetic waves and surface characteristics. The term surface roughness in microwave region refers to the microrelief of the soil surface representing a scale range from millimeters to decimeter. For smooth surfaces, geometrical variations of surface irregularities and volume discontinuities are small in comparison to wavelength of microwaves. Two important coefficients characterized the surface roughness are the RMS surface height or standard deviation of height $(\sigma)$ and roughness correlation length $(l)$. Both $\sigma$ and $l$ are statistical parameters commonly used in the description of surface roughness. Here, $\sigma$ corresponds to vertical scale roughness while $l$ corresponds to horizontal scale roughness. Behari [11] explained that the roughness parameter $h$ may be defined by the ratio of surface RMS height $(\sigma)$ and horizontal correlation length $(l)$. According to Choudhury et al. [18] semiempirical model for comparatively smoother surfaces such as stubble, pastures, and rolled agricultural fields, a typical value of $h$ is equal to 0.1 , and for rough fields such as those recently tilled agricultural field, the possible value of $h$ is equal to 0.5 .

\section{Experimental Procedure and Theory}

The soil of local profile of Alwar (semiarid region of northwest India situated at the verge of Thar Desert at latitude and longitude $27^{\circ} 34^{\prime} 0^{\prime \prime} \mathrm{N} / 76^{\circ} 36^{\prime} 0^{\prime \prime} \mathrm{E}$ ) has been used for experimentation. $\varepsilon^{\prime}$ and $\varepsilon^{\prime \prime}$ of soil at different bulk densities are determined by wave guide cell method. The textural composition obtained by the methods of sieving and sedimentation of the soil is: clay $=7.20 \%$, silt $=21.50 \%$, and sand $=71.30 \%$, respectively. Different bulk densities of the same soil in the cell are obtained by filling the wave guide with an equal volume but a different mass of soil. In order to achieve a uniform bulk density throughout the whole wave guide, the repeated fractional filling and hammering method is used for particular set of observation. Variations in the bulk density of the soil in the cell are achieved between 1.3 and $2.0 \mathrm{gm} / \mathrm{cm}^{3}$.

The values of $\varepsilon^{\prime}$ and $\varepsilon^{\prime \prime}$ at different bulk densities are determined at a single microwave frequency $9.78 \mathrm{GHz}$ and at temperature $37.0^{\circ} \mathrm{C}$ using Two-Point Method described 
elsewhere $[11,20]$. The temperature is according to standard field condition of the area in summer and monsoon season. The experimental set-up, theory, and procedure are the same as used earlier by other researchers [21, 22]. The dielectric constant (real and imaginary parts) values of soil are determined using the shift in minima of the standing wave pattern formed in the slotted section of a rectangular waveguide excited in $\mathrm{TE}_{10}$ mode. The schematic diagram of the experimental set-up is shown in Figure 1.

In the present investigations, sample holder or dielectric cell filled with soil (column height $l_{\varepsilon}$ ) is assembled with the microwave bench. The standing wave pattern in the slotted section of the waveguide alters in comparison to the empty dielectric cell. Let the positions of first minima in the slotted section be displaced due to the presence of dielectric material (soil) from $D_{R}$ to $D$. For loaded wave guide cell VSWR is measured at the position $D$ of first minima in the slotted section by VSWR meter. Reflection coefficient $\Gamma$ is obtained by VSWR values. The measurements of $D, D_{R}$, and $\lambda_{g}$ are made using a slotted line section with movable probe carriage with an accuracy of $\pm 0.01 \mathrm{~cm}$. The length of soil sample $l_{\varepsilon}$ in the wave guide is measured with the help of a microscope with an accuracy of $\pm 0.001 \mathrm{~cm}$.

Using Two-Point Method the real and imaginary parts of complex permittivity of soil samples are given by the following:

$$
\begin{aligned}
& \varepsilon^{\prime}=\frac{G_{\varepsilon}+\left(\lambda_{g} / 2 a\right)^{2}}{1+\left(\lambda_{g} / 2 a\right)^{2}}, \\
& \varepsilon^{\prime \prime}=\frac{B_{\varepsilon}}{1+\left(\lambda_{g} / 2 a\right)^{2}},
\end{aligned}
$$

where $G_{\varepsilon}$ and $B_{\varepsilon}$ are the conductance and susceptance offered by the soil sample, respectively. $a$ is the wider dimension of waveguide $a=\left(\lambda_{c} / 2\right)$. $\lambda_{g}$ is guide wavelength given by (3):

$$
\lambda_{g}=\frac{\lambda_{0} \lambda_{c}}{\sqrt{\lambda_{c}^{2}-\lambda_{0}^{2}}}
$$

where $\lambda_{0}$ is the free space wave length of microwave.

The complex permittivity is given by the relation (4) as follows:

$$
\varepsilon_{r}=\varepsilon^{\prime}-j \varepsilon^{\prime \prime} .
$$

The admittance $V_{\varepsilon}$ offered by the soil sample can be given by (5) as follows:

$$
V_{\varepsilon}=G_{\varepsilon}+j B_{\varepsilon} .
$$

The admittance $V_{\varepsilon}$ is obtained by using the values of $T$ and $\tau$ as given by (6):

$$
V_{\varepsilon}=\left(\frac{T}{k l_{\varepsilon}}\right)^{2} \angle 2\left(\tau-90^{\circ}\right),
$$

where $T$ and $\tau$ are the radial magnitude and argument angle of the complex transcendental number.

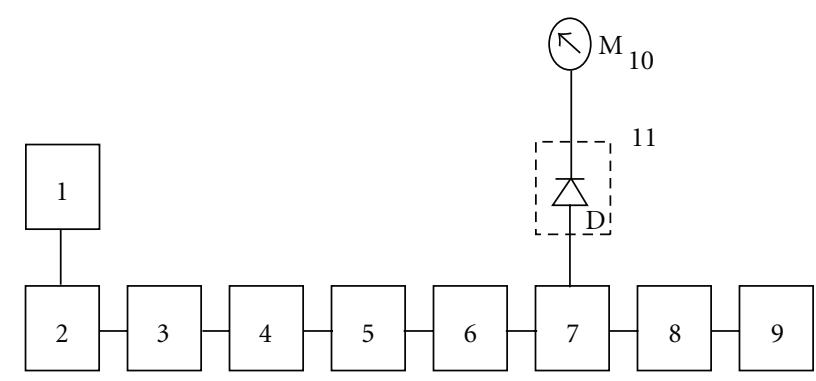

(1) Klystron power supply

(2) Klystron tube

(3) Isolator

(4) Frequency meter

(5) E-H tunner

(6) Variable attenuator

FIGURE 1: X-Band experimental set-up.

We have obtained the values $T$ and $\tau$ on solving the complex transcendental equation (7) given as follows:

$$
C \angle-\psi=\frac{\tanh (T \angle \tau)}{(T \angle \tau)} .
$$

The solution of the previous equation is available in the literature both in graphical and in tabular form. Here we have used extensive plots of these solutions as given by Von-Hippel [23].

The complex number $C \angle-\psi$ is related to $k, \phi, \Gamma$, and $l_{\varepsilon}$ by the following:

$$
C \angle-\psi=-\frac{j}{k l_{\varepsilon}} \times \frac{1-|\Gamma| e^{j \phi}}{1+|\Gamma| e^{j \phi}},
$$

where $k=2 \pi / \lambda_{g}$ is the propagation constant of microwaves inside the wave guide. $\phi=2 k\left(D-D_{R}-l_{\varepsilon}\right)$ is the phase difference between travelling waves when the waveguide is loaded with sample and empty.

The $\varepsilon^{\prime}$ and $\varepsilon^{\prime \prime}$ for bulk soil are given by Peplinski model [4] as follows:

$$
\begin{gathered}
\mathcal{\varepsilon}^{\prime}=\left[1+\frac{\rho_{b}}{\rho_{s}}\left(\varepsilon_{s}^{\alpha}-1\right)+\theta^{\beta^{\prime}} \varepsilon_{\mathrm{fw}}^{\prime \alpha}-\theta\right]^{1 / \alpha}, \\
\mathcal{\varepsilon}^{\prime \prime}\left[\theta^{\beta^{\prime \prime}} \varepsilon_{\mathrm{fw}}^{\prime \prime \alpha}-\theta\right]^{1 / \alpha},
\end{gathered}
$$

where $\varepsilon_{s}$ and $\varepsilon_{w}$ are the dielectric constants of the soil solid and water; $\alpha$ is an empirical shape factor equal to $0.65 ; \theta$ is the volumetric soil moisture fraction; $\rho_{b}\left(\mathrm{~g} \mathrm{~cm}^{-3}\right)$ is soil bulk density; $\rho_{s}\left(\approx 2.66 \mathrm{~g} \mathrm{~cm}^{-3}\right)$ is soil particle density. $\beta^{\prime}$ and $\beta^{\prime \prime}$ are empirical texture dependent factors. $\varepsilon_{\mathrm{fw}}^{\prime}$ and $\varepsilon_{\mathrm{fw}}^{\prime \prime}$ are the real and imaginary parts of dielectric constant for free water given by the Debye model [24].

According to Klein and Swift [25] and Stogryn [26] the static dielectric constant $\left(\varepsilon_{w 0}\right)$ and relaxation time $\left(\tau_{W}\right)$ of pure water in Debye model [24] are strongly dependent on temperature. We have used the values of static dielectric constant $\left(\varepsilon_{w 0}\right)$ and the relaxation time $\left(\tau_{W}\right)$ at $37^{\circ} \mathrm{C}$ according to Klein and Swift [25] and Stogryn [26] modification. 
By using the emissivity model [13] treating uniformity of soil subsurface temperature and dielectric profile, Kirchoff's reciprocity theorem relates the polarized emissivity $\left(e_{p}\right)$ for bare and smooth soil surfaces which can be given by.

$$
e_{p}(\theta)=1-R_{p}(\theta)
$$

where $R_{p}(\theta)$ is the polarized Fresnel reflectivity derived from electromagnetic theory [27]. The horizontal and vertical components of reflectivity are given by (11) as follows:

$$
\begin{gathered}
R_{h}(\theta)=\left[\frac{\cos \theta-\sqrt{\varepsilon_{r}-\sin ^{2} \theta}}{\cos \theta+\sqrt{\varepsilon_{r}-\sin ^{2} \theta}}\right]^{2}, \\
R_{\nu}(\theta)=\left[\frac{\varepsilon_{r} \cos \theta-\sqrt{\varepsilon_{r}-\sin ^{2} \theta}}{\varepsilon_{r} \cos \theta+\sqrt{\varepsilon_{r}-\sin ^{2} \theta}}\right]^{2},
\end{gathered}
$$

where the symbols have their usual meanings.

The Rough surface emissivity is given by a semiempirical model of Choudhury et al. [18] followed by (12) as follows:

$$
e^{\prime}=1-\left[\{1-e\} \cdot \exp ^{-\left(h \cos ^{2} \theta\right)}\right],
$$

where $e^{\prime}$ and $e$ are the rough and smooth surface emissivities, respectively and $h$ is roughness parameter depending upon the geometrical properties of the soil surface, polarization, and frequency of the microwave.

\section{Results and Discussion}

The variations of $\varepsilon^{\prime}$ and $\varepsilon^{\prime \prime}$ values of soil samples at varying bulk density ( 1.3 to $2.0 \mathrm{gm} / \mathrm{cm}^{3}$ ) determined by experimentation and Peplinski model [4] are shown in Figure 2. It is evident from Figure 2 that both $\varepsilon^{\prime}$ and $\varepsilon^{\prime \prime}$ increase as bulk density of the soil increases.

Dielectric permittivity of a material is its bulk property which defines the interaction of electromagnetic wave with material. When a dielectric media are placed in electric field, the number of induced dipoles per unit volume defines the real part of dielectric constant. In presence of oscillating electric field, these dipoles try to align themselves with the field direction. For a given value of the gravimetric moisture content, increase in the bulk density will increase the volumetric soil moisture content and thus the soil dielectric constant. Further, $\varepsilon^{\prime \prime}$ increases with bulk density of soil due to increase in rotational inertia and viscosity. Hence, there is an increasing lag between the forcing field and orientation of the dipole, resulting into more absorption power in the soil and causing enhancement in dielectric loss.

The experimental values of $\varepsilon^{\prime}$ are slightly lower than those of model-predicted values, can be explained as the moisture present in the soil, and exist in two forms, bound water, and free water [7]. Dielectric constant of free water is higher than that of bound water. The Peplinski et al. [4] model considers that only free water is present in moist soil. Hence, estimated values are higher than thoses of experimental values. Further, it is evident from Figure 1 that experimental values of dielectric loss $\left(\varepsilon^{\prime \prime}\right)$ are in close agreement with the values predicted by the model.

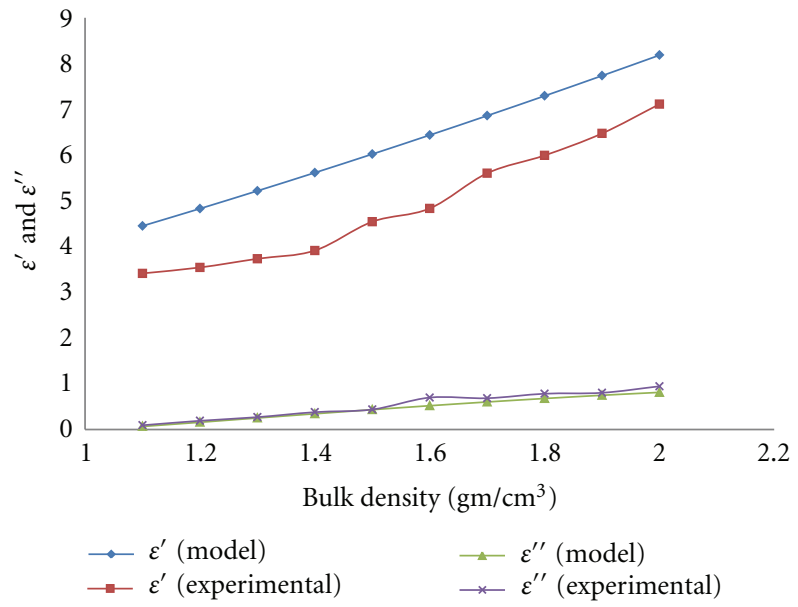

Figure 2: Variations of $\varepsilon^{\prime}$ and $\varepsilon^{\prime \prime}$ of soil with respect to bulk density of the soil.

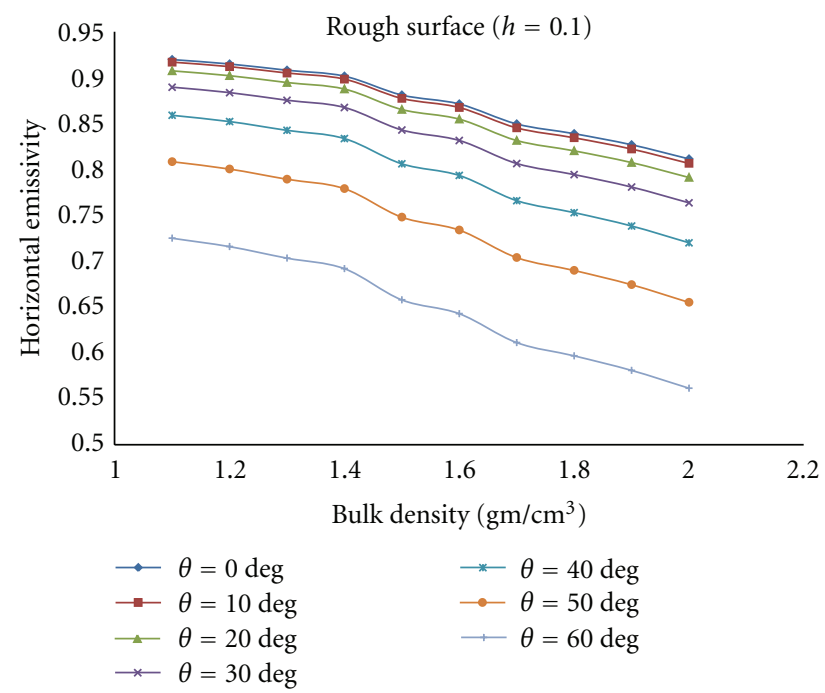

FIGURE 3: Variations of horizontal emissivity of rough surface $(h=$ $0.1) \mathrm{v} / \mathrm{s}$ bulk density of soil.

Variations of horizontal and vertical components of emissivity $\left(e_{h}\right.$ and $\left.e_{\nu}\right)$ with bulk density of soil for real surfaces at roughness parameters $h=0.1$ and 0.5 are shown in Figures 3, 4, 5, and 6. From Figures 3-6 it reveals that $e_{h}$ and $e_{\nu}$ decrease as the bulk density $\left(\rho_{b}\right)$ of the soil increases. This may be explained as the increase in bulk density leads to an increase in the soil dielectric constant resulting into an increase in the soil reflectivity (from the Fresnel equations), which eventually leads to a decrease in the emissivity. Further, the values of emissivity $\left(e_{h}\right.$ and $e_{\nu}$ ) of real surface at higher roughness $(h=0.5)$ are greater than those of smooth surface $(h=0.1)$. The increase in emissivity $e_{h}$ and $e_{\nu}$ with surface roughness can be attributed to the increase in soil surface area that interfaces with the air and, thus, transmits the upwelling energy. This is because of the fact that the exposure area of the surface increases with increase in the roughness. 


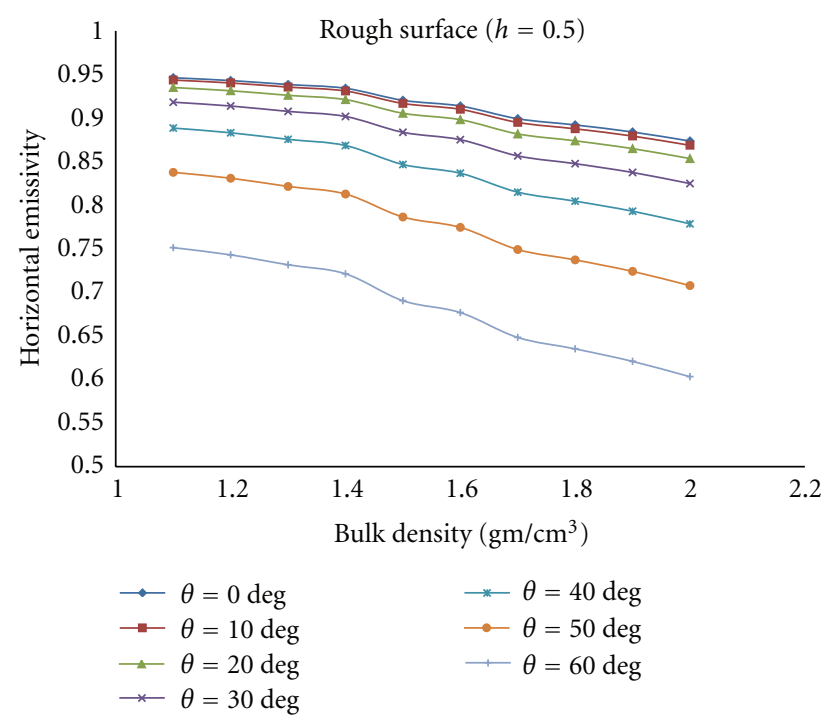

FIGURE 4: Variations of horizontal emissivity of rough surface $(h=$ $0.5) \mathrm{v} / \mathrm{s}$ bulk density of soil.

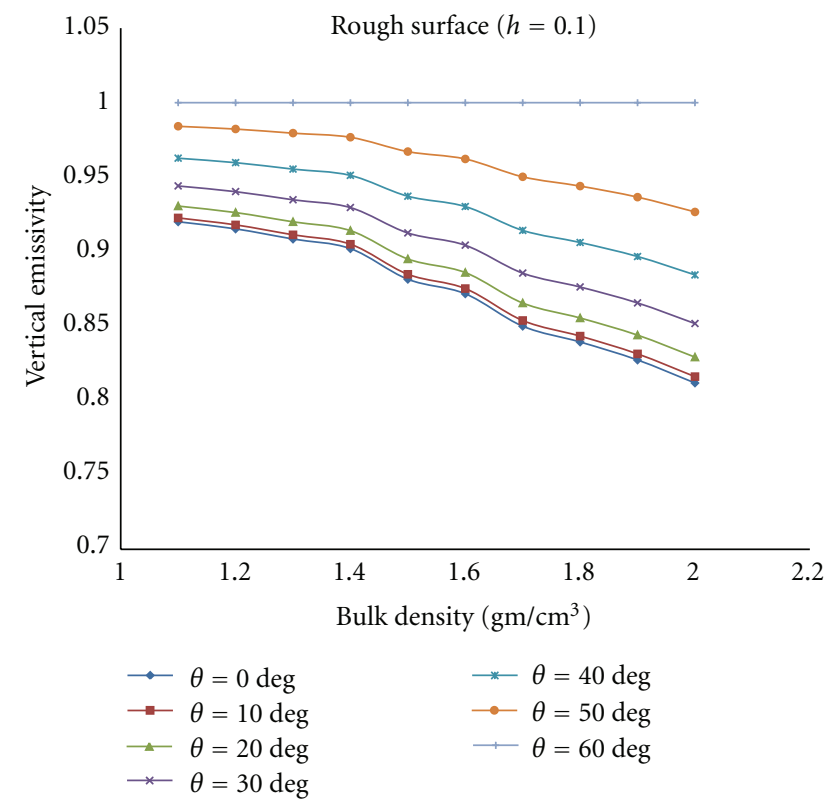

FIGURE 5: Variations of vertical emissivity of rough surface $(h=0.1)$ v/s bulk density of soil.

Figures 3 and 4 reveal that the value of $e_{h}$ for any particular value of bulk density decreases as the angle of observation $(\theta)$ increases. The $e_{h}$ is maximum at normal incident angle $\left(\theta=0^{\circ}\right)$ and decreases towards grazing direction. This is because of the obliquity conditions of Fresnel relations. According to Fresnel relations, horizontal reflectivity is lowest in normal direction and increases as obliquity increases. Hence, $e_{h}$ decreases as the angle of observation increases but the variations of $e_{v}$ with respect to $(\theta)$ are quite different in comparison to the corresponding variations of $e_{h}$. Here

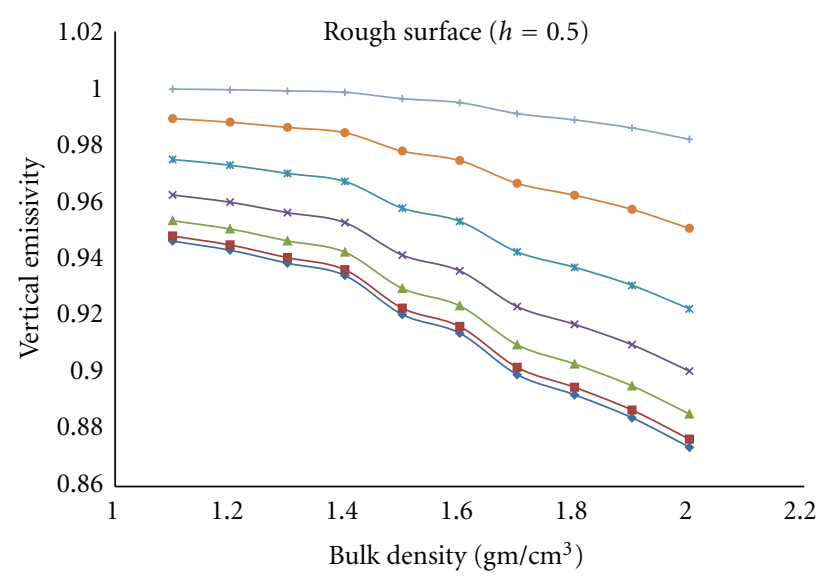

$$
\begin{aligned}
& \because \theta=0 \mathrm{deg} \quad \because \theta=40 \mathrm{deg} \\
& \because \theta=10 \mathrm{deg} \quad \longrightarrow \theta=50 \mathrm{deg} \\
& \neg \theta=20 \mathrm{deg} \quad \longrightarrow \theta=60 \mathrm{deg} \\
& \star * \theta=30 \mathrm{deg}
\end{aligned}
$$

FIGURE 6: Variations of vertical emissivity of rough surface $(h=0.5)$ $\mathrm{v} / \mathrm{s}$ bulk density of soil.

the $e_{v}$ increases as the $(\theta)$ increases up to $60^{\circ}$. This may be due to the fact that Fresnel reflectivity for vertical polarized microwaves decreases or emissivity increases up to Brewster angle, as described by Calla et al. [28].

\section{Conclusions}

Bulk density of soil directly affects the real and imaginary parts of complex permittivity $\left(\varepsilon^{\prime}\right.$ and $\left.\varepsilon^{\prime \prime}\right)$. Hence, the different physical properties of soil such as soil structure, soil water (storage and movement), soil aeration, and soil strength and porosity dependent on bulk density of soil will affect the dielectric properties of the soil. Further, microwave emission from the soil surface inhibits as bulk density of soil increases and the emissivity of real surface increases as the roughness of surface increases.

\section{Acknowledgment}

The authors are thankful to the University Grants Commission (UGC), New Delhi, India for providing financial, assistance to carry out the research work under the scheme of major research project sanctioned to R. A. Jangid.

\section{References}

[1] M. A. Malicki, R. Plagge, and C. H. Roth, "Improving the calibration of dielectric TDR soil moisture determination taking into account the solid soil," European Journal of Soil Science, vol. 47, no. 3, pp. 357-366, 1996.

[2] C. H. Roth, M. A. Malicki, and R. Plagge, "Empirical evaluation of the relationship between soil dielectric constant and volumetric water content as the basis for calibrating soil moisture measurements by TDR," Journal of Soil Science, vol. 43, no. 1, pp. 1-13, 1992. 
[3] M. C. Dobson, F. T. Ulaby, M. A. El-Rayes, and M. T. Hallikainen, "Microwave dielectric behavior of wet soil-part II: dielectric mixing models," IEEE Transactions on Geoscience and Remote Sensing, vol. GE-23, no. 1, pp. 35-46, 1985.

[4] N. R. Peplinski, F. T. Ulaby, and M. C. Dobson, "Dielectric properties of soils in the $0.3-1.3-\mathrm{GHz}$ range," IEEE Transactions on Geoscience and Remote Sensing, vol. 33, no. 3, pp. 803807, 1995.

[5] M. T. Hallikainen, F. T. Ulaby, M. C. Dobson, and M. A. El-Rayes, "Microwave dielectric behavior of wet soil-part I: empirical models and experimental observations," IEEE Transactions on Geoscience and Remote Sensing, vol. GE-23, no. 1, pp. 25-34, 1985.

[6] P. Hoekstra and A. Delaney, "Dielectric properties of soils at UHF and microwave frequencies," Journal of Geophysical Research, vol. 79, pp. 1699-1708, 1974.

[7] J. R. Wang and T. J. Schmugge, "An empirical model for the complex dielectric permittivity of soils as a function of water content," IEEE Transactions on Geoscience and Remote Sensing, vol. GE-18, no. 4, pp. 288-295, 1980.

[8] J. P. Wigneron, J. C. Calvet, T. Pellarin, A. A. Van de Griend, M. Berger, and P. Ferrazzoli, "Retrieving near-surface soil moisture from microwave radiometric observations: current status and future plans," Remote Sensing of Environment, vol. 85, no. 4, pp. 489-506, 2003.

[9] N. Baghdadi, O. Cerdan, M. Zribi et al., "Operational performance of current synthetic aperture radar sensors in mapping soil surface characteristics in agricultural environments: application to hydrological and erosion modelling," Hydrological Processes, vol. 22, no. 1, pp. 9-20, 2008.

[10] J. Álvarez-Mozos, J. Casalí, M. González-Audícana, and N. E. C. Verhoest, "Assessment of the operational applicability of RADARSAT-1 data for surface soil moisture estimation," IEEE Transactions on Geoscience and Remote Sensing, vol. 44, no. 4, pp. 913-923, 2006.

[11] J. Behari, Microwave Dielectric Behaviour of Wet Soils, Anamaya Publishers, New-Delhi, India, 2005.

[12] F. T. Ulaby, R. K. Moore, and A. K. Fung, Microwave Remote Sensing Active and Passive, vol. 3, Artech House, Boston, Mass, USA, 1986.

[13] W. Peake, "Interaction of electromagnetic waves with some natural surfaces," IRE Transactions on Antennas and Propagation, vol. 7, pp. 2582-2590, 1959.

[14] F. T. Ulaby, R. K. Moore, and A. K. Fung, Microwave Remote Sensing: Active and Passive, vol. 2, Addison-Wesley, Reading, Mass, USA, 1982.

[15] M. Nolan and D. R. Fatland, "Penetration depth as a DInSAR observable and proxy for soil moisture," IEEE Transactions on Geoscience and Remote Sensing, vol. 41, no. 3, pp. 532-537, 2003.

[16] T. Schmugge, P. Gloersen, T. Wilheit, and F. Geiger, "Remote sensing of soil moisture with microwave radiometers," Journal of Geophysical Research, vol. 19, no. 2, pp. 317-323, 1974.

[17] T. J. Schmugge, T. J. Jackson, A. D. Nicks, G. A. Coleman, and E. T. Engman, "Soil moisture updating and microwave remotesensing for hydrological simulation," in Proceedings of the Symposium on Hydrological Forecasting, Oxford, UK, 1980.

[18] B. J. Choudhury, T. J. Schmugge, R. W. Newton, and A. Chang, "Effect of surface roughness on the microwave emission from soils," Journal of Geophysical Research, vol. 84, no. 9, pp. 56995706, 1979.

[19] J. P. Wigneron, A. Chanzy, Y. H. Kerr et al., "Evaluating an improved parameterization of the soil emission in L-MEB,"
IEEE Transactions on Geoscience and Remote Sensing, vol. 49, no. 4, pp. 1177-1189, 2008.

[20] M. Saucher and J. Fox, Handbook of Microwave Measurements, vol. 2, John Wiley \& Sons, New York, NY, USA, 503.

[21] O. P. N. Calla, S. Agarwal, S. K. Agarwalla, R. Bhattacharjee, and A. Kalita, "Comparative study of the methods of measurement of dielectric constant at microwave frequencies for dry and wet soil," Indian Journal of Radio \& Space Physics, vol. 32, no. 2, pp. 108-113, 2003.

[22] D. H. Gadani and A. D Vyas, "Measutment of complex dielectric constant of soil of Gujrat at X and C band microwave frequencies," Indian Journal of Radio \& Space Physics, vol. 37, pp. 221-229, 2008.

[23] A. Von Hippel, Dielectrics and Waves, Wiley, New York, NY, USA, 1954.

[24] P. Debye, Polar Molecules, Dover Publications, New York, NY, USA, 1929.

[25] L. A. Klein and C. T. Swift, "An improved model for the dielectric constant of sea water at microwave frequencies," IEEE Transactions on Antennas and Propagation, vol. 25, no. 1, pp. 104-111, 1977.

[26] Stogryn A, "Equations for calculating the dielectric constant of saline water," IEEE Transactions on Microwave Theory and Techniques, vol. 19, no. 8, pp. 733-736, 1971.

[27] J. A. Kong, Electromagnetic Wave Theory, Wiley-Interscience, New York, NY, USA, 2nd edition, 1990.

[28] O. P. N. Calla, A. Baruah, B. Das, K. P. Mishra, M. Kalita, and S. S. Haque, "Emission and scattering behaviour of dry soils from northeast India," Indian Journal of Radio and Space Physics, vol. 33, no. 5, pp. 321-328, 2004. 

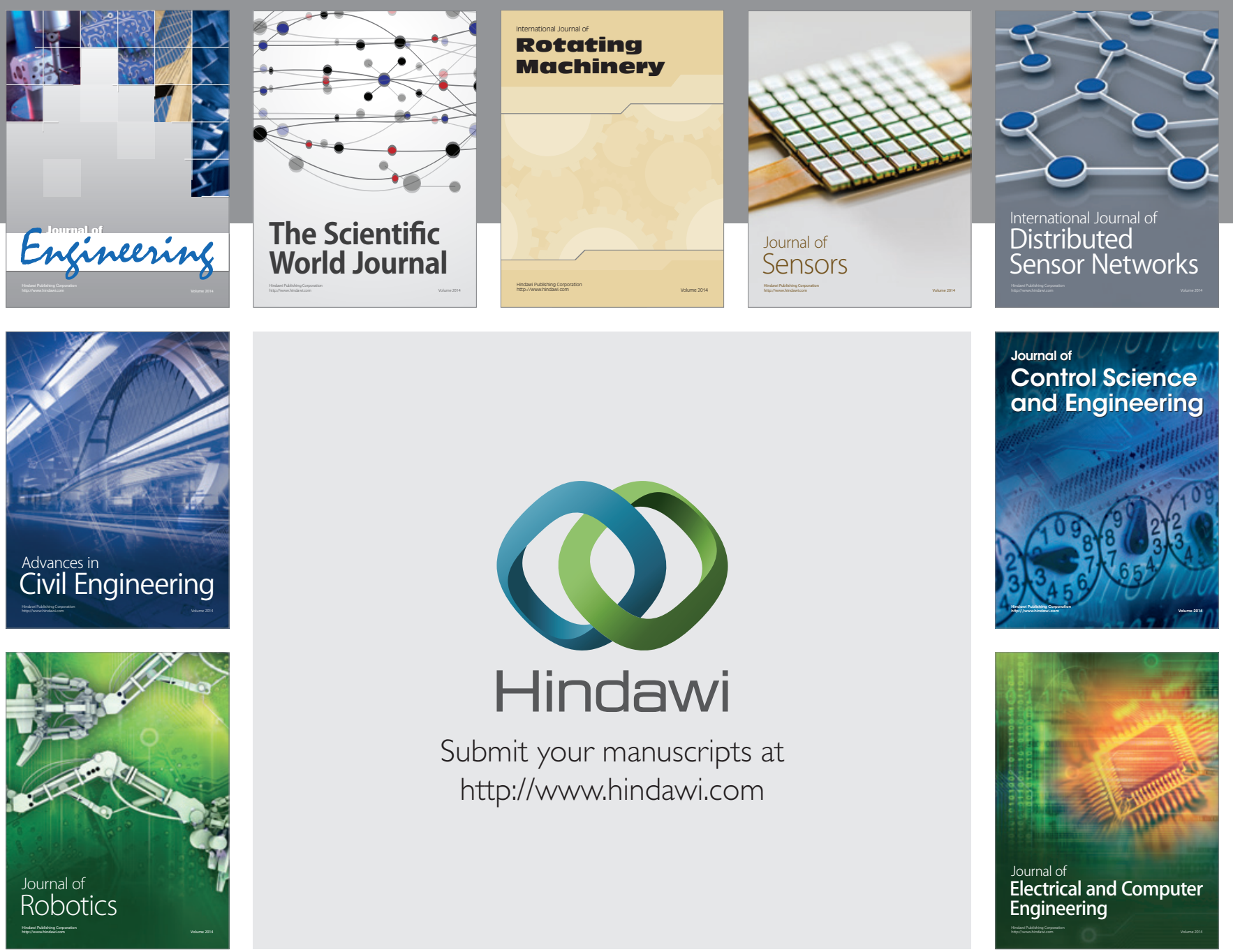

Submit your manuscripts at

http://www.hindawi.com
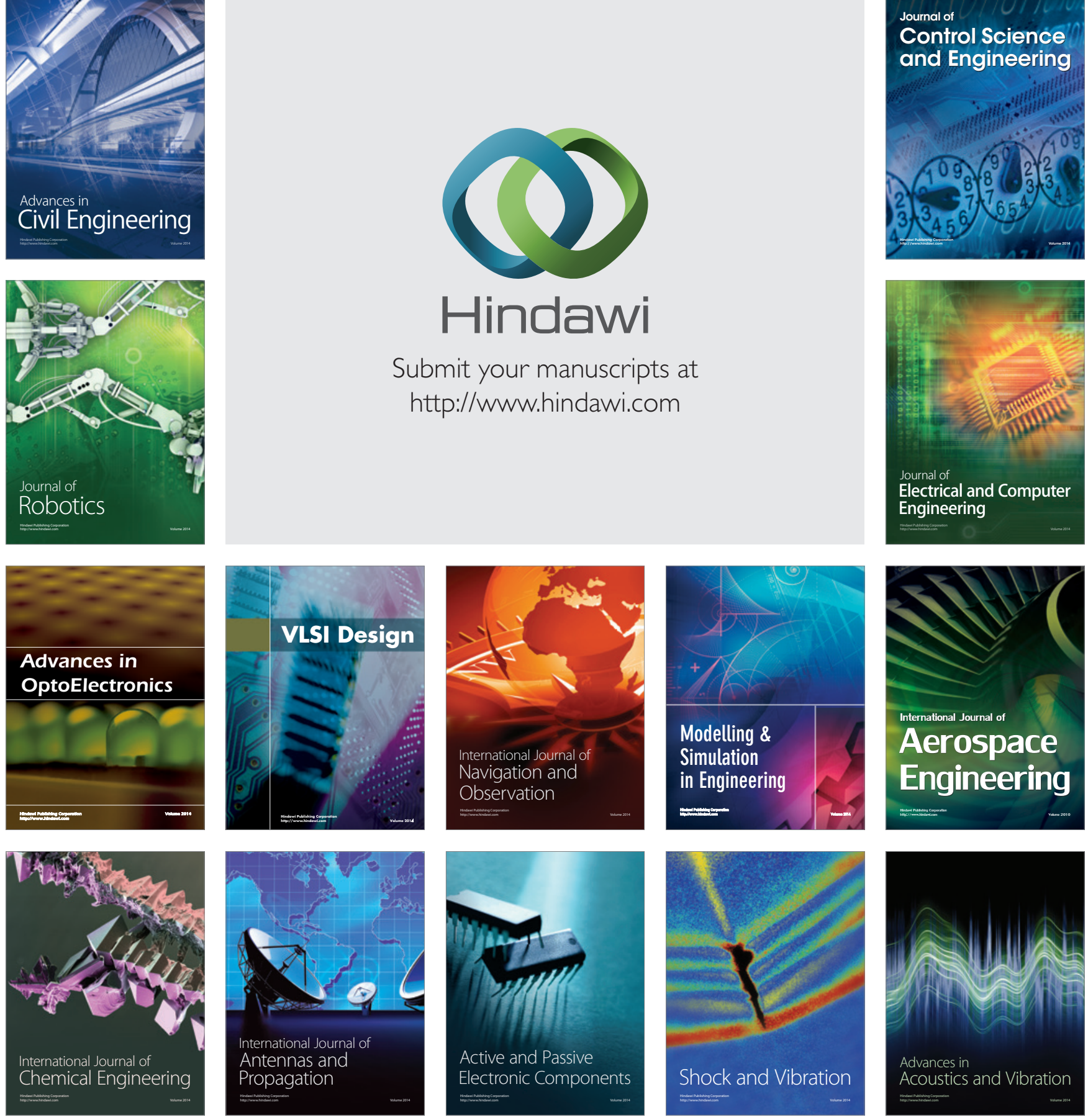